\title{
Study on Water Absorptivity and Frost Resistance Performance of Self-ignition Coal Gangue Autoclaved Aerated Concrete
}

\section{Xinyu Cong}

Harbin Institute of Technology

\section{Yiqiu Tan}

Harbin Institute of Technology

Shuang Lu ( $\nabla$ hitlu@126.com )

Harbin Institute of Technology https://orcid.org/0000-0001-8700-0254

\section{Zhaojia Wang}

state key laboratory of solid waste reuse for building materials

Tianyong Huang

Beijing building materials academy of science research

\section{Research Article}

Keywords: Self-ignition coal gangue, AAC, porosity, water absorptivity, frost resistance performance

Posted Date: February 18th, 2021

DOl: https://doi.org/10.21203/rs.3.rs-207256/v1

License: (c) (1) This work is licensed under a Creative Commons Attribution 4.0 International License. Read Full License 
[Title Page]

\section{Study on water absorptivity and frost resistance performance}

\section{of self-ignition coal gangue autoclaved aerated concrete}

Xinyu Cong ${ }^{1}$, Yiqiu Tan ${ }^{1}$, Shuang. $\mathrm{Lu}^{2,3 *}$, Zhaojia Wang ${ }^{4 * *}$, Tianyong Huang ${ }^{4}$

${ }^{1}$ School of Transportation Science and Engineering, Harbin Institute of Technology, Harbin 150090, Heilongjiang, China

${ }^{2}$ School of Civil Engineering, Harbin Institute of technology, Harbin 150090, China

${ }^{3}$ Key Lab of Structures Dynamic Behavior and Control of the Ministry of Education, 9 Harbin Institute of Technology, Harbin 150090, China

${ }^{4}$ State Key Laboratory of Solid Waste Reuse for Building Materials, Beijing Building 11 Materials Academy of Science Research, Beijing 100041, China

*Correspondence: hitlu@126.com

${ }^{2}$ School of Civil Engineering, Harbin Institute of technology, Harbin 150090, China

${ }^{3}$ Key Lab of Structures Dynamic Behavior and Control of the Ministry of Education, 9 Harbin Institute of Technology, Harbin 150090, China

** Correspondence: wangzhaojia@bbmg.com.cn

${ }^{4}$ State Key Laboratory of Solid Waste Reuse for Building Materials, Beijing Building 11 Materials Academy of Science Research, Beijing 100041, China 


\title{
Study on water absorptivity and frost resistance performance
}

\section{of self-ignition coal gangue autoclaved aerated concrete}

\author{
Xinyu Cong ${ }^{1}$, Yiqiu Tan ${ }^{1}$, Shuang. $\mathrm{Lu}^{2,3}{ }^{*}$, Zhaojia Wang ${ }^{4 * *}$, Tianyong Huang ${ }^{4}$
}

\section{Abstract}

Self-ignition coal gangue (SCG) used as one of precursors to fabricate aerated autoclaved concrete (AAC). Aiming at studying water absorptivity and frost resistance performance of self-ignition coal gangue aerated autoclaved concrete (SCGAAC), three-period water absorbing tests and freezing-thawing tests were carried out and the corresponding results were recorded and analyzed. In order to modify the water absorptivity of SCGAAC, foam stabilizer was applied to adjust pore structure while calcium stearate was expected to change hydrophilic feature of CG. It was demonstrated that the compressive strength of SCGAAC containing foam stabilizer or calcium stearate declined at different levels, although the porosity became lower slightly. For water absorptivity, foam stabilizer failed to decrease the water content at any period and even increased water absorbing rates. Calcium stearate controlled water absorbing rate successfully but the ultimate water content hardly reduced. All of the SCGAAC samples exhibited intact appearance after 50 freezing-thawing cycles and showed excellent frost resistance performance. Three models were proposed to predict water absorptivity and frost resistance performance of SCGAAC and the corresponding prediction results matched test resulted well.Keywords: Self-ignition coal gangue; AAC; porosity; water absorptivity; frost resistance performance 


\section{Introduction}

In recent years, autoclaved aerated concrete (AAC) has been commonly used as construction material by virtue of its functional performance [1-6], in particular, thermal insulation and energy efficiency [7-9]. AAC comprised of cement, fly ash, lime and finegrained aggregates has been produced in Asia, Europe and Americas since it once turned into creation in Sweden in 1930s [10]. However, its excellent thermal and sound insulation properties are shadowed when considering of high water absorption. It was reported that the mass loss and compressive strength loss of water-saturated AAC reached $1.5 \%$ and $16.6 \%$ after suffering from 50 freeze-thaw cycles [11]. Frost resistance of AAC deteriorated with the interior moisture increasing and it was easy to generate frostheaving cracks and denudation [12]. Meanwhile, Miloš Jerman [13] also observed that a thermal conductivity coefficient of AAC in capillary water saturation became as much as six times of that in a dry state.

As a porous product, pore structure has a strong effect on the moisture distribution of AAC $[14,15]$. In the past few decades, some principles related to water transportation in porous AAC system were presented [13-18]. For example, it was found that water vapor diffusion and capillary suction dominated in dry conditions and high humidity circumstances, respectively. Water absorbing and transmitting caused by capillarity in porous materials like AAC were defined as a sorptivity process which was governed by the unsaturated flow theory [8]. The overall capillary absorption was well described as two processes: a capillary absorption in aerated pores achieved gravitational equilibrium rapidly; and a slow capillary absorption into the matrix pores [19].

With the intention of consuming self-ignition coal gangue (SCG) in construction 
materials, AAC using self-ignition coal gangue (SCGAAC) as one of precursors was fabricated and studied [20]. Mechanical performance and failure mechanism of the SCGAAC significantly depended on its micro structure as well as formation of reaction products, especially on the generation of tobermorite. In order to further elaborate the properties of SCGAAC with high humidity, water absorption and frost resistance were studied. Specifically, the compressive strength and mass change of SCGAAC samples subjected to freeze-thaw cycles were tested and the corresponding prediction models related to porosity were proposed.

\section{Materials and Experiments}

\subsection{Raw materials}

The precursors of SCGAAC comprised of SCG, ordinary Portland cement (PC), lime (L) and gypsum (G). The chemical composition of the raw materials was listed in Table 1. In this study, the SCG was resourced from Heilongjiang, China. The as-received SCG aggregates with a particle size of 10-30 mm were milled to form SCG powder which sieved through an $80 \mu m$ sieve. Naphthalene-based superplasticizer (FDN) was selected to adjust the slurry expansion (SE) of SCGAAC pastes. Aluminum powder (AP) was used as a foaming agent in AAC system. 
Table 1 Chemical composition and loss on ignition of precursors

\begin{tabular}{cccccccc}
\hline Oxide & $\mathrm{CaO}$ & $\mathrm{SiO}_{2}$ & $\mathrm{Al}_{2} \mathrm{O}_{3}$ & $\mathrm{Fe}_{2} \mathrm{O}_{3}$ & $\mathrm{MgO}$ & $\mathrm{SO}_{3}$ & Loss on \\
(wt.\%) & & & & & & & ignition \\
\hline $\mathrm{SCG}$ & 1.18 & 61.02 & 23.55 & 6.70 & 0.52 & - & 2.5 \\
$\mathrm{PC}$ & 62.31 & 21.05 & 5.50 & 3.92 & 1.72 & 2.66 & - \\
$\mathrm{L}$ & 85.33 & 3.28 & - & - & 5.20 & - & - \\
$\mathrm{G}$ & 29.93 & 7.31 & 11.70 & 0.60 & 0.18 & 38.84 & 9.62 \\
\hline
\end{tabular}

\subsection{Chemical agents and mix ratios}

Two chemical admixtures added into the mixes when fabricating SCGAAC samples. A foam stabilizer $(\mathrm{F})$ was used to reduce bubble cracking during the stirring process and optimize pore structure of hardened AAC. The other chemical agent, calcium stearate $(\mathrm{C})$, was regarded as a waterproof agent to decrease water absorption. The two chemical agents were expected to reduce water absorption in different ways. Aiming at improve the pore structure of AAC, the foam stabilizer mainly stopped bubbles merging and reduced connected pores. In addition, calcium stearate achieved a hydrophobic AAC matrix that was instrumental in absorbing little water. The dosage of the chemical agents and the mix ratios of SCGAAC were presented in Table 2. 
Table 2 Mix proportions of SCGAAC

\begin{tabular}{|c|c|c|c|c|c|c|}
\hline \multirow{2}{*}{$\begin{array}{c}\text { SCG } \\
(\mathrm{g})\end{array}$} & \multirow{2}{*}{$\begin{array}{l}\text { L } \\
(\mathrm{g})\end{array}$} & \multirow{2}{*}{$\begin{array}{l}\text { PC } \\
(\mathrm{g})\end{array}$} & \multirow{2}{*}{$\begin{array}{l}\text { G } \\
(\mathrm{g})\end{array}$} & \multicolumn{2}{|c|}{$\mathrm{AP}$} & \multirow{2}{*}{$\mathrm{W} / \mathrm{P}^{\# 1}$} \\
\hline & & & & $(\%)$ & (g) & \\
\hline 1300 & 559 & 481 & 78 & 1.3 & 3.14 & 0.50 \\
\hline \multirow{2}{*}{ Label } & \multicolumn{2}{|c|}{ Chemical agents } & SE & \multicolumn{2}{|c|}{ FDN } & $\rho^{\# 2}$ \\
\hline & type & (g) & $(\mathrm{mm})$ & $(\%)$ & (g) & $(\mathrm{kg} / \mathrm{m} 3)$ \\
\hline$f-1$ & - & - & 250 & 1.40 & 33.85 & 750 \\
\hline$f-2$ & - & - & 290 & 1.60 & 38.69 & 635 \\
\hline$f-3$ & - & - & 320 & 1.80 & 43.52 & 634 \\
\hline$f-4$ & $\mathrm{~F}$ & 0.15 & 250 & 1.40 & 33.85 & 704 \\
\hline$f-5$ & $\mathrm{~F}$ & 0.15 & 290 & 1.60 & 38.69 & 710 \\
\hline$f-6$ & $\mathrm{~F}$ & 0.15 & 320 & 1.80 & 43.52 & 693 \\
\hline$f-7$ & $\mathrm{C}$ & 72.5 & 250 & 1.60 & 38.69 & 660 \\
\hline$f-8$ & $\mathrm{C}$ & 72.5 & 290 & 1.70 & 41.11 & 658 \\
\hline$f-9$ & $\mathrm{C}$ & 72.5 & 320 & 1.85 & 44.73 & 613 \\
\hline
\end{tabular}

\subsection{Specimens}

The mix procedures of SCGAAC was applied as the method mentioned in a preceding study [20]. Slurry expansions (SE) was a measurement index reflecting workability of fresh AAC pastes and it was found that the SE had an influence on the density and pore structure of hardened AAC [20]. In this study, all of the fresh pastes were controlled the SE at 250, 290 and $320( \pm 5) \mathrm{mm}$ respectively through adjusting the dosage of FDN. The SCGAAC samples were moulded in $100 \mathrm{~mm}^{3}$ cube metal moulds. The fabrication process 
and the curing protocol referred to [20].

\subsection{Test methods}

Super depth of field microscope (SDFM) was applied to characterize the pore structure of SCGAAC. In order to accurately identify the pores and matrix, the samples for the pore characterization were pretreated through ink painting and titanium dioxide powder filling. Fig. 1 showed the contrast of the original sample and pretreated samples. The captured image of specimens can be obtained and then processed in the dark field microscope environment by SDFM.

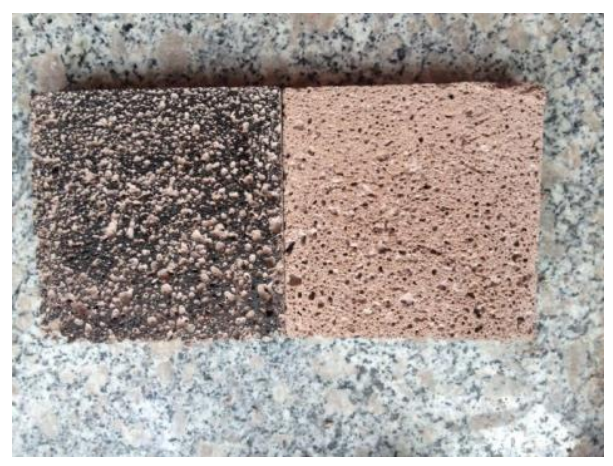

a)

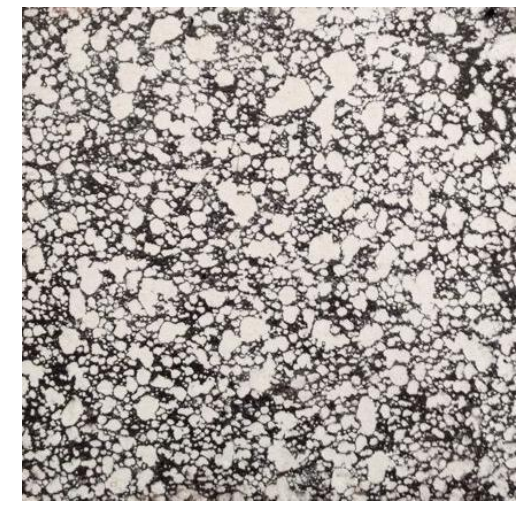

b)

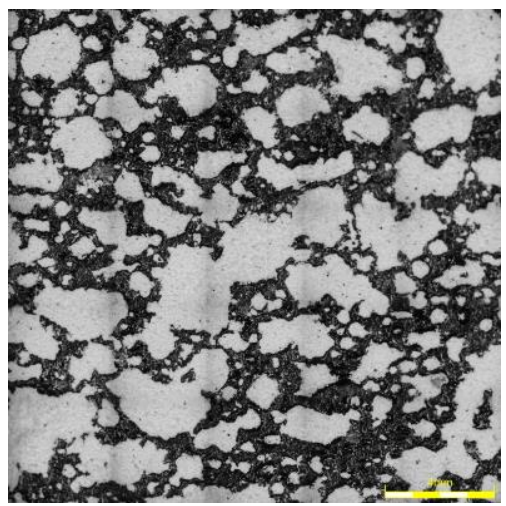

c)

Fig. 1 Super depth of field microscope (SDFM) images for pore characterization of SCGAAC: a) black-painting slice vs. original slice; b) pore-filling slice; c) capture image. 
Compressive strength results were obtained from testing SCGAAC cubes with $10( \pm 2)$ wt $\%$ water content. For the water absorption tests, drying treatment at $105 \pm 5{ }^{\circ} \mathrm{C}$ for $24 \mathrm{~h}$ was performed before absorptivity tests. Fig. 2 exhibited the testing procedure for the water absorbing behavior of the SCGAAC samples. The water was periodically added into a tank to soak the pre-dried samples. Specifically, the depth of water for the first 24hour absorption test was as high as $3 \mathrm{~cm}$ and the mass change of the samples were recorded. The water depths for the second and third 24-hour absorption tests were assigned at $7 \mathrm{~cm}$ and $12 \mathrm{~cm}$, respectively.

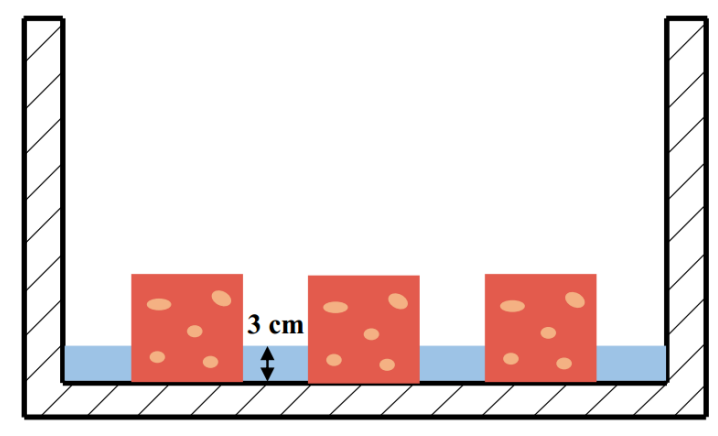

a)

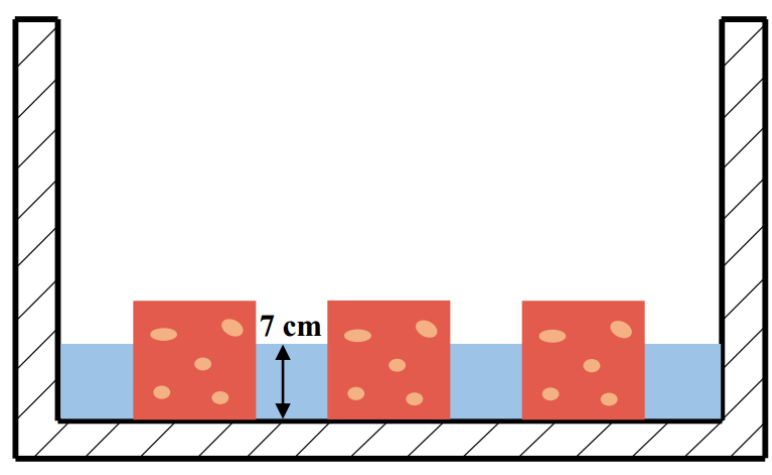

b) 


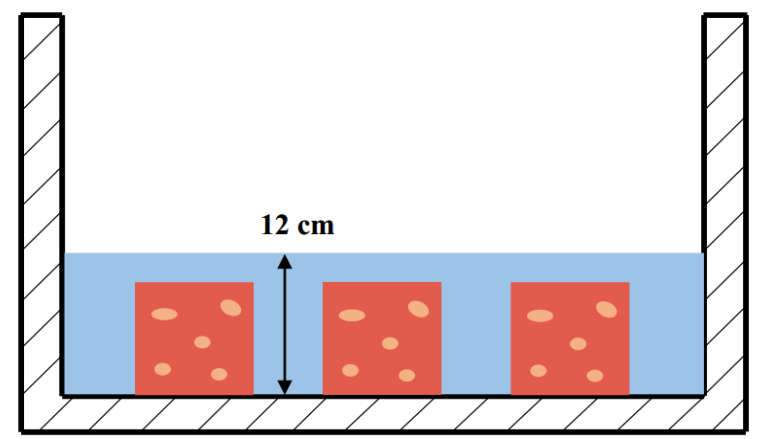

c)

Fig. 2 The protocol of water absorption test: a) the water volume for the first $24 \mathrm{~h}$; b) the water volume for the second $24 \mathrm{~h}$; c) the water volume for the third $24 \mathrm{~h}$.

The measuring process of water content and saturated water absorptivity conforms to GB/T 11969-2008 [21]. The water absorptivity $W_{\mathrm{R}}$ can be calculated as Eq. (1):

$$
W_{R}=\frac{M_{g}-M_{0}}{M_{0}} \times 100 \%
$$

where $M_{\mathrm{g}}$ is the mass of sample after water absorption and $M_{0}$ is the mass of sample in absolute dry status.

Frost resistance performance of SCGACC was tested according to $G B / T$ 11969-2008 [21]. One freezing and thawing cycle contained two stages: the water-soaked samples froze in air at $-20 \pm 2{ }^{\circ} \mathrm{C}$ for $4 \mathrm{~h}$; and then the temperature rose to $20 \pm 2{ }^{\circ} \mathrm{C}$ and the samples immerged in water for $4 \mathrm{~h}$ to thaw. The compressive strength and mass change were recorded after the SCGAAC samples were subjected to 50 freezing and thawing cycles. 


\section{Results and Discussion}

\subsection{Pore structure of SCGAAC}

According to the captured pictures of SCGAAC slices, three main pore parameters were computed by the OLYMPUS Stream software connected with the SDFM, including porosity, pore-size distribution and average length-width ratio (ALwR) of the pores. The results related to the pores of the SCGAAC samples were shown in Table 3. It was observed that porosity increased with the sample SE becoming larger. For the samples without any chemical agents, the porosity rose by approximate $16 \%$ when the SE increased from $250 \mathrm{~mm}$ to $320 \mathrm{~mm}$. The $\mathrm{f}-1$ sample showed the lowest pore content $(45.93 \%)$ and the highest density $\left(750 \mathrm{~kg} / \mathrm{m}^{3}\right)$. The porosity increased obviously as the SE was enlarged, especially the percentage of the pores within 0.5-2 mm.

The chemical agents improved the pore structure of SCGAAC at different levels through lowering the porosity and mesopores. The foam stabilizer was a type of surfactant that reduced the surface tension of the slurry and forming stable bubbles. Much more bubbles formed and existed easily in the thick slurry with $250 \mathrm{~mm} \mathrm{SE}$ when the F agent was used. As the slurry becoming thinner ( $320 \mathrm{~mm} \mathrm{SE})$, a part of bubbles inclined to crack in low viscosity pastes and the F agent intensified this tendency. Hence, the F agent adjusted the bubble status and content in the slurry with different SE and the thick slurry witnessed an obvious effectiveness. The agent $\mathrm{C}$ also showed an effect on adjusting pore structure of the SCGAAC samples. For all of the samples with different SE, the samples containing the $\mathrm{C}$ agent had a lower porosity than those containing the $\mathrm{F}$ agent. It was found that the small and large pores increased while the mesopores reduced. 
Table 3 Characterization of pores in SCGAAC

\begin{tabular}{cccccc}
\hline & & \multicolumn{3}{c}{ Pore-size distribution (\%) } & \\
\cline { 3 - 5 } Label & Porosity (\%) & Fine pore & Mesopore & Large pore & ALwR \\
& & $<0.5 \mathrm{~mm}$ & $0.5 \sim 2 \mathrm{~mm}$ & $>2 \mathrm{~mm}$ & \\
\hline $\mathrm{f}-1$ & 45.93 & 2.68 & 94.89 & 2.43 & 1.61 \\
$\mathrm{f}-2$ & 56.17 & 2.43 & 92.16 & 5.41 & 1.70 \\
$\mathrm{f}-3$ & 62.82 & 6.58 & 89.69 & 3.73 & 1.65 \\
$\mathrm{f}-4$ & 54.33 & 3.25 & 89.79 & 6.96 & 1.65 \\
$\mathrm{f}-5$ & 57.55 & 3.85 & 89.51 & 6.64 & 1.60 \\
$\mathrm{f}-6$ & 58.96 & 3.64 & 89.26 & 6.92 & 1.65 \\
$\mathrm{f}-7$ & 53.06 & 4.34 & 87.26 & 8.40 & 1.61 \\
$\mathrm{f}-8$ & 54.87 & 5.07 & 86.87 & 8.06 & 1.61 \\
$\mathrm{f}-9$ & 55.39 & 4.98 & 87.26 & 7.76 & \\
\hline
\end{tabular}

ALwR was a parameter reflected the degree of pores connecting. Assuming that independent bubbles in the slurry were sphere and the ALwR equals 1 if there is no any connection happening among the bubbles. The ALwR exceeds 1 when the bubbles merge near a direction. Therefore, this parameter is an index for understanding the connection degree of pores in the SCGAAC. The ALwR results showed no obvious relationships with the porosity results. It was worth noting that the SCGAAC including the $\mathrm{C}$ agent had the lowest ALwR values at any SE levels, especially for the thin slurry samples.

\subsection{Mechanical properties of SCGAAC}

Compressive strength was tested to assess the mechanical properties of the SCGAAC. As exhibited in Fig. 3, the chemical admixtures showed an influence on the compressive 
strength. The foam stabilizer almost brought no harm in compressive strength of the SCGAAC while calcium stearate obviously decreased the compressive strength. This was because that the density of the SCGAAC containing calcium stearate was lower than that of the others. The corresponding density results were listed in Table 2. The foam stabilizer kept small bubbles suspending in the slurry rather than rising up and cracking through adjusting the surface tension of fresh slurry. The bubbles evenly distributed in the matrix to form relatively dense system, which resulted in the high compressive strength.

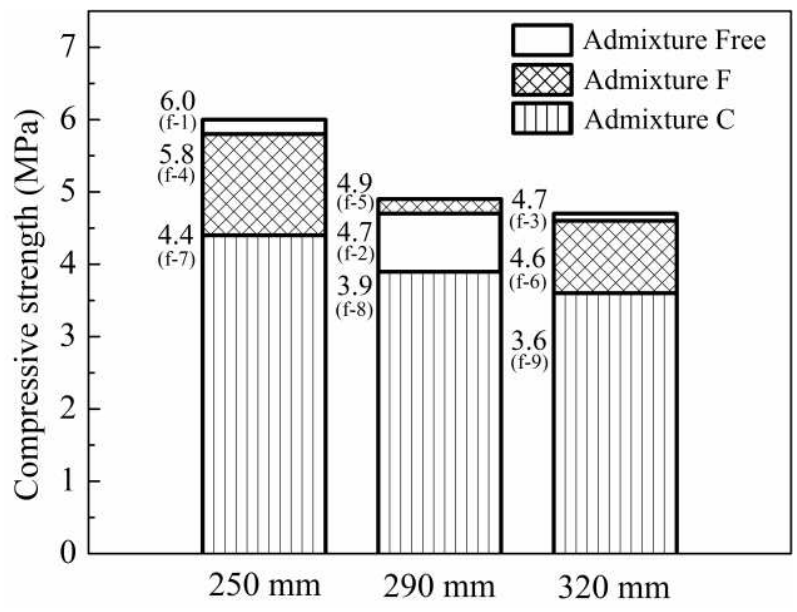

Fig. 3 Compressive strength of SCGAAC.

Compared to the admixture free samples, the compressive strength of the SCGAAC comprising the agent $\mathrm{C}$ declined visibly. The compressive strength was even lower than 4.0 MPa when the SE was over $290 \mathrm{~mm}$. The SCGAAC containing the agent $\mathrm{C}$ with the lowest porosity, according to the pore parameters presented in Table 3, had the lowest density. It was reasonable to infer that calcium stearate had a negative influence on the matrix of SCGAAC. 


\subsection{Water absorptivity of SCGAAC}

Water-absorbing rates of the SCGAAC samples were shown in Fig. 4. The water absorption curves for the $\mathrm{f}-1, \mathrm{f}-2$ and $\mathrm{f}-3$ presented the identical trends. During the three water uptake periods, the samples with the $290 \mathrm{~mm}$ SE obtained the highest water content. The water content of these three samples after 72-hour absorbing were at a similar level, ranging from $47.3 \%$ to $52.3 \%$. Although the foam stabilizer enhanced the compressive strength, the water absorptivity failed to be controlled by using the foam stabilizer. As shown in Fig. 4, f-4, f-5 and f-6 absorbed more volume of water in every period compared to the counterparts without any admixture. For the f-6 sample, the water content after $72 \mathrm{~h}$ was slightly lower than $60 \%$. Two potential reasons explain this results. The first one is the formation of interconnecting capillary pores because of using the foam stabilizer, and the other one is the matrix becoming more hydrophilic.

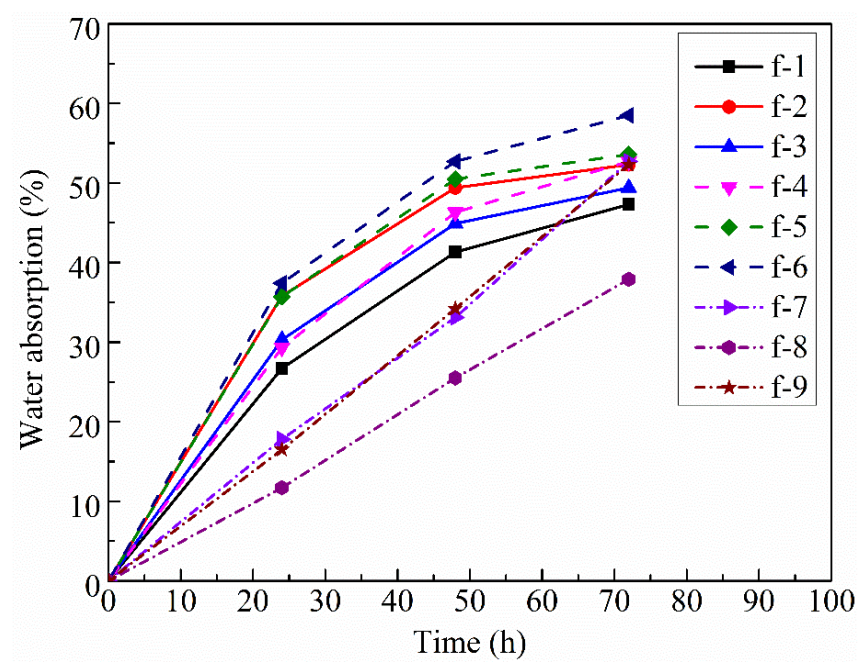

Fig. 4 Water absorptivity of SCGAAC.

Compared to the foam stabilizer, calcium stearate effectively controlled the water absorption of the SCGAAC within $48 \mathrm{~h}$. Although the 72-hour water contents were near the others, the water-uptake of the SCGAAC comprising calcium stearate was obviously 
slow during the first $24 \mathrm{~h}$. Calcium stearate was a strong waterproof agent for the SCGAAC, which can be seen according to the slopes of water absorption curves in Fig. 4. For the samples $\mathrm{f}-1$ to $\mathrm{f}-\mathrm{6}$, the water absorption rates were variable over the three periods, where the initial water uptake slopes were steep and the rates gradually tended to be flat at last. When it came to the samples with calcium stearate, the trend of water absorption was different. The samples kept absorbing water with an invariable rate over the whole duration. The lowest water absorption of the SCGAAC came from the f-8 sample with $37.9 \%$ of the water content after $72 \mathrm{~h}$.

The different trend of water absorption was mainly from hydrophobicity caused by calcium stearate. It was difficult for water to infiltrate into the CG matrix when the water was initially on contact with the matrix. It took time to permeate into the matrix during the immerging period. For the samples modified by calcium stearate, moisture transport along the pore path because of capillarity was a minor factor for water absorbing process. Although the driving force for water uptake was capillarity, it was water-holding capacity that decided how much moisture can be transported up. The SCGAAC samples without calcium stearate absorbed water quickly when water was on contact with the matrix and the water content for the local matrix under the water line nearly reached saturation over the first period. The rate of moisture transport was slower than that of water uptake, therefore, the curves for $\mathrm{f}-1$ to $\mathrm{f}-6$ showed decreased slopes. For the f- 7 to $\mathrm{f}-\mathrm{9}$ samples, water absorbing rates kept a constant throughout, which demonstrated that the water content for the matrix was unsaturated and it reached a dynamic equilibrium between the moisture transport and water uptake. Therefore, calcium stearate was an effective waterproof agent for SCGAAC and it was efficient to decrease water absorbing rate and 
reduce water content at early time.

\subsection{Frost resistance of SCGAAC}

Fig. 5 and Fig. 6 showed the mass change $(\Delta m / m)$ and compressive strength change of the SCGAAC samples subjected to freezing-thawing cycles. The $\Delta m / m$ results of the samples after 25 cycles were exhibited in Fig. 5 (a). All of the samples showed an increased mass after 25 freezing-thawing cycles and the highest increment reached $6.53 \%$ from the f-8 samples. It was worth noting that the SCGAAC with calcium stearate increased more mass than the other two types of SCGAAC in any SE status. Combined with the water absorption curves shown in Fig. 4, it can be inferred that the $\mathrm{f}-7$ to f-9 samples being unsaturated after 72-hour water absorbing and water kept permeating in the matrix during the following freezing-thawing cycles. That explained the highest mass increment for the samples with calcium stearate. For the other two SCGAAC samples, the mass increment showed a similar level around 3.0\%.

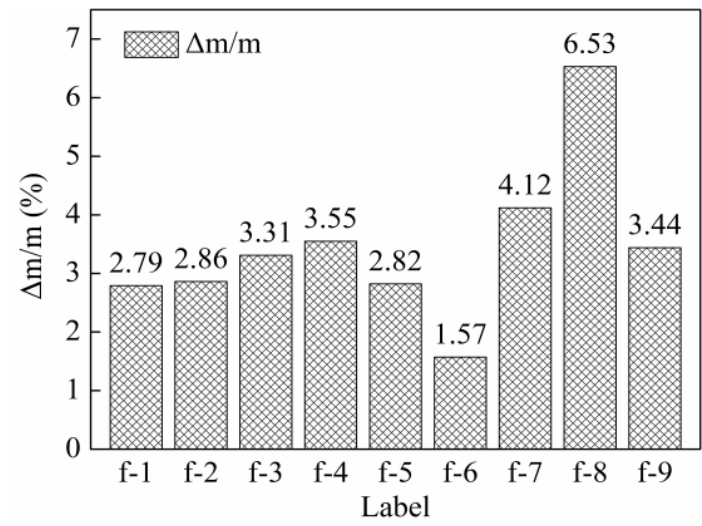

a)

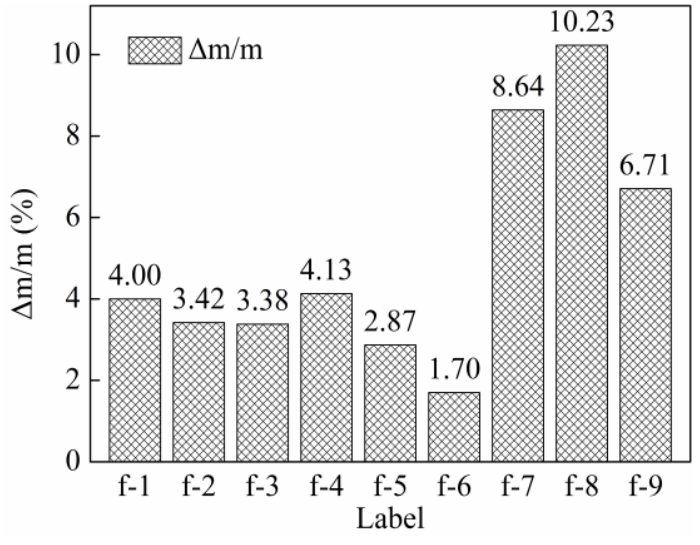

b)

Fig. 5 Mass change of SCGAAC subjected to a different number of freezing-thawing circles: a) after 25 freezing-thawing cycles; and b) after 50 freezing-thawing cycles.

Fig. 5 b) presented the mass change of the SCGAAC after 50 cycles. All of the samples 
still kept increasing the mass after 50 freezing-thawing cycles, and all of the samples showed intact appearance. The SCGAAC without calcium stearate increased the mass marginally after 50 cycles instead of developing mass loss. The steady mass increase occurred in the SCGAAC comprising calcium stearate, where the highest increment went beyond $10 \%$ (f-8). It demonstrated that calcium stearate modified the matrix hydrophobic and controlled the water permeating. $\mathrm{CG}$ had strong water absorbing ability itself and it was ease for CG to seize surrounding water. Calcium stearate probably changed the surface properties of $\mathrm{CG}$ and water infiltrating postponed. Although this blocking effect temporarily slowed water absorbing of SCGAAC, the following moisture transport through pore channels was hindered notably.

In order to further examine the difference caused by freezing-thawing cycles, the samples experienced 50 freezing-thawing cycles dried at $105^{\circ} \mathrm{C}$ to reach a constant mass. The absolutely dried mass were recorded and the compressive strength were tested, and the corresponding comparisons were shown in Fig. 6. It can be seen, in Fig. 6 (a), the absolutely dried mass change $\Delta m_{\mathrm{d}} / m$ was a positive value for the each sample, which meant growth of the SCGAAC matrix happened. This weight increment likely attributed to cement hydration during the freezing-thawing period. The autoclave curing protocol for the SCGAAC was heating at $196{ }^{\circ} \mathrm{C}(1.1 \mathrm{MPa})$ in water vapor for $8 \mathrm{~h}$, during which most precursors would react and generate reaction products. However, CG inclined to hold and consume water as much as possible when the precursors were mixed with water. It took hours for cement particles to hydrate and the free water would be insufficient for complete hydration taking place at that time. The subsequent freezing-thawing tests appropriately supplied water for the unhydrated cement. This was the most likely reason 
for the absolutely dried weight increment of the SCGAAC.

The compressive strength of the SCGAAC was also different with the counterparts experienced freezing-thawing cycles. As shown in Fig. 6 (b), the f-1 to f-6 samples enhanced the compressive strength at different levels while the f-7 to f-9 samples with calcium stearate had a decreased compressive strength. Herein, the freezing processes were performed in air rather than in water, therefore the unsaturated pores supplied sufficient room for releasing frost heaving deformation. Moreover, all of the samples were undamaged visibly and had increased mass. It can be considered that the frost heaving damage of the SCGAAC hardly happened. The decreased compressive strength of the samples possibly resulted from permeation stress as water infiltrated through the water-proof matrix formed by calcium stearate.

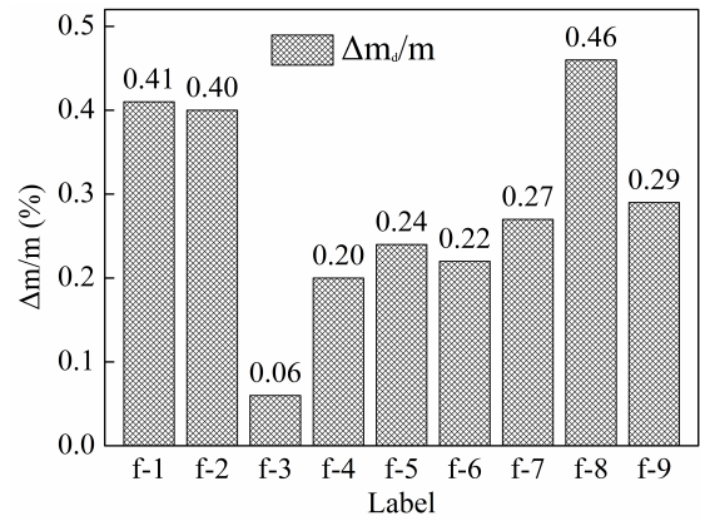

a)

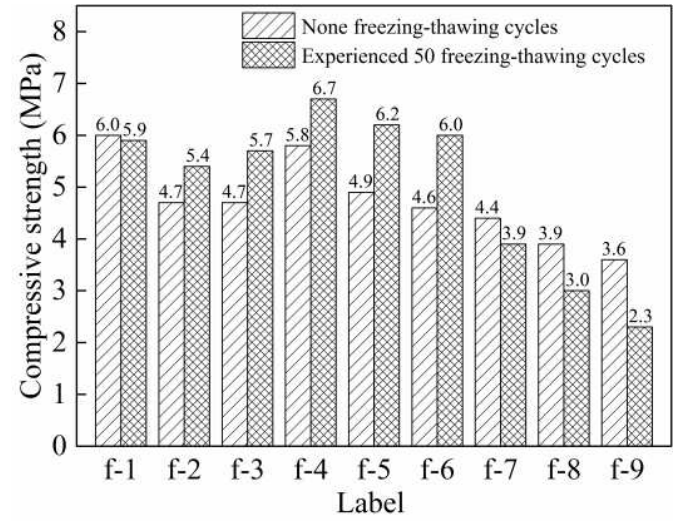

b)

Fig. 6 Difference of SCGAAC subjected to 50 freezing-thawing cycles: a) absolutely dried mass; and b) compressive strength.

\subsection{Predictive models}

On the basis of the test results, the water absorptivity of the SCGAAC could be related 
to the matrix as well as pore parameters. Herein, the fine pore $(<0.5 \mathrm{~mm})$ fraction and the ALwR were applied to fit a predictive model of water absorptivity of SCGAAC. The proposed model was shown as Eq. (2):

$$
W_{s}=0.75 \ln (A L w R)+0.95 P_{0.5}+R_{1}
$$

where $W_{s}$ is the 72-hour water absorptivity of the SCGAAC; $P_{0.5}$ is the percentage of fine pores ( $<0.5 \mathrm{~mm})$; and $R_{1}$ is a parameter related to effectiveness of chemical agents, equal to 0.1 as no chemical agent being used and equal to 0.15 and 0.12 for foam stabilizer and calcium stearate, respectively. The prediction values from Eq. (2) matched well to the test results. For porous AAC, pore structure strongly influenced water absorptivity. The pores with large diameters hardly contributed to water absorbing process, therefor the fraction of those pores with small size were considered to build the proposed model. The isolated pores failed to convey water as an effective driving force during water absorption and the $\mathrm{ALwR}$ was used to reflect the effect of pore interconnection on water absorptivity. $R_{1}$, a parameter related to material, was applied to show the difference caused by chemical agents.

For the frost resistance performance, compressive strength variation $(\Delta \sigma)$ and normalized mass increment $(\Delta m / m)$ were chosen as two assessment indexes. Herein, two critical factors, strength-to-density ratio $(\sigma / \rho)$ and the total porosity $\left(P_{\mathrm{t}}\right)$, were used to build the corresponding models. Strength-to-density ratio reflected the effectiveness of matrix as a backbone of porous $\mathrm{AAC}$ and pore volume supplied potential room for frost heaving stress transferring. A parameter, $R_{2}$, was applied to show the difference caused by chemical agents. $R_{2}$ for the SCGAAC without any admixture assigned to a value of 10.8 , and $R_{2}$ assigned to 10.9 and 10.1 when foam stabilizer and calcium stearate were used 
respectively. The secondary hydration of cement and influence of chemical agent on mechanical properties were taken into account when assign specific values to the $R_{2}$. Accordingly, the compressive strength variation of SCGAAC experiment freezingthawing cycles can be predicted using Eq. (3):

$$
\Delta \sigma=7.26 \ln \left(P_{t}\right)-\frac{1}{250 \cdot \sigma / \rho}+R_{2}
$$

The normalized mass increment of SCGAAC experienced freezing-thawing cycles can be related to the strength-to-density ratio, the fine pore porosity as well as material parameter $R_{3}$. These three factors corporately adjusted the normalized mass increment, and assigned the values of $1.10,1.05$ and 0.95 to $R_{3}$ for chemical agent free SCGAAC, SCGAAC with foam stabilizer and SCGAAC with calcium stearate, respectively. Eq. (4) was proposed to predict the normalized mass increment of SCGAAC:

$$
\frac{\Delta m}{m}=1.14 \cdot \mathrm{e}^{-\frac{\sigma}{\rho}}+\frac{1}{\left(64 \cdot P_{0.5}\right)^{2}}-R_{3}
$$

Fig. 7 presented the comparison between the test results and prediction results obtained from Eq. (2) to (4). It can be seen that the proposed models showed similar results to development of the SCGAAC experienced water absorption and freezing-thawing cycles. The model results matched to the test results at a good level. To some extent, the proposed models supplied a guide for SCGAAC design. The water absorbing properties and frost resistance performance can be obtained when the basic physic properties of SCGAAC were tested. 


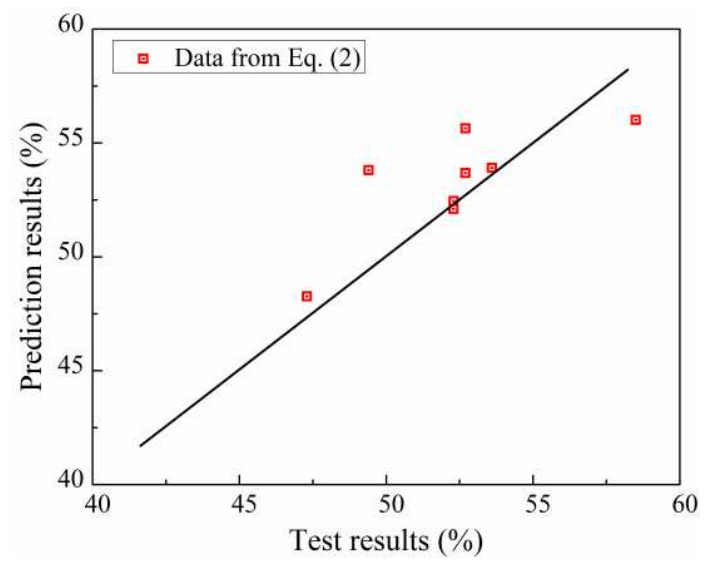

a)

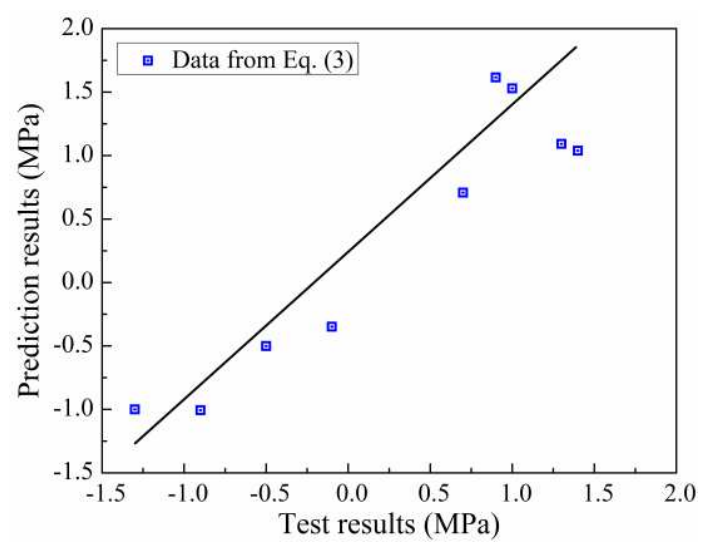

b)

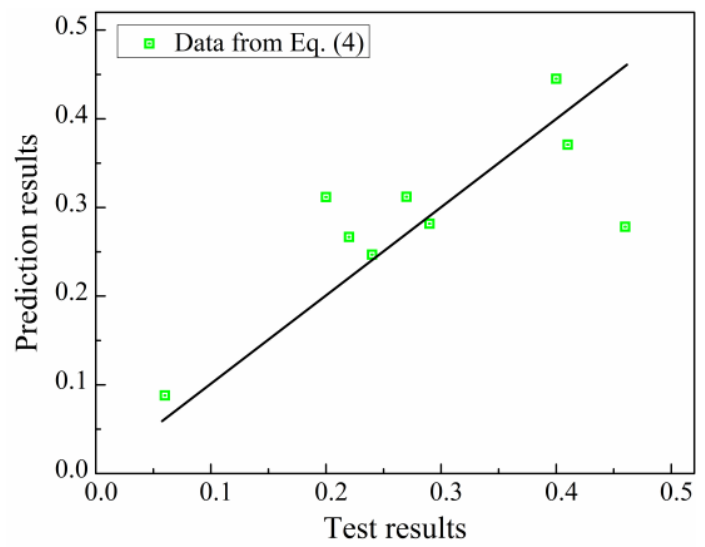

c)

Fig. 7 Comparison between prediction results and test results: a) data from Eq. (2); b) data from Eq. (3); and c) data from Eq. (4). 


\section{Conclusions}

Focusing on the water absorptivity and frost resistance performance of SCGAAC, 9 SCGAAC samples with different SE and chemical agents were tested, including porosity, water content and rate, and mass change experienced freezing-thawing cycles etc. According to the tests and corresponding analysis, the main conclusions were drawn as follow:

1) Foam stabilizer achieved dense SCGAAC through adjusting surface tension of the slurry to hold more isolated bubbles suspending in the fresh paste. The density of SCGAAC comprising the foam stabilizer increased when the SE was beyond $290 \mathrm{~mm}$. Calcium stearate had an effect on changing hydrophilicity of the matrix material and decreased the density of SCGAAC. Both foam stabilizer and calcium stearate decreased the porosity of SCGAAC effectively.

2) Compressive strength of SCGAAC was influenced by SE and chemical agents. The compressive strength declined with the increasing SE and the highest compressive strength was from the SCGAAC with SE of $250 \mathrm{~mm}$. Foam stabilizer almost had no influence on compressive strength while calcium stearate obviously decreased the compressive strength.

3) SCGAAC had high water absorptivity due to the porous matrix and high water uptake capacity of CG. Foam stabilizer slightly increased the water absorption and water absorbing rates at any period, especially the rate of first 24-hour period. The water absorbing rate became flat gradually with time. The water absorbing rate became obviously slow because of the water proof property of calcium stearate and it showed a constant rate throughout the whole duration. The ultimate water content reached the similar level to the counterpart of admixture free samples because of water permeation.

4) SCGAAC exhibited excellent frost resistance performance. All of the samples kept intact appearance after experiencing 50 freezing-thawing cycles and the absolute dried mass of the samples slightly increased. Most of the SCGAAC 
developed the compressive strength to the higher values and the samples comprising foam stabilizer increased the compressive strength obviously. By contrast, compressive strength of the SCGAAC containing calcium stearate deteriorated by 0.5-1.3 MPa after 50 freezing-thawing cycles.

5) The models proposed for predicting water absorptivity, mass change and strength change matched well to the corresponding test results. These models would reasonably predict water absorbing ability and frost resistance performance through some basic physic parameters.

\section{Acknowledgements}

The author acknowledges the editorial assistance and the constructive criticism by the anonymous reviewers.

\section{Author's contributions}

$\mathrm{XC}$ performed the design of the study and collection, analysis, and interpretation of data, and was a major contributor in writing the manuscript. YT and SL supervised the entire project. ZW proposed the experimental program. TH helped to conduct laboratory tests and review the manuscript. All authors read and approved the final manuscript.

\section{Funding}

The authors would like to acknowledge funding support from Heilongjiang Postdoctoral Fund No. LBH-Z20137 and National Natural Science Foundation of China No. 51872064. The authors also would like to acknowledge the State Key Laboratory of Solid Waste Reuse for Building Materials SWR-2020-005. 


\section{Availability of data and materials}

All data have been presented in the Commentary.

\section{Ethics approval and consent to participate}

Not applicable.

\section{Consent for publication}

Not applicable.

\section{Competing interests}

The authors declare that they have no competing interests.

\section{Author details}

1 School of Transportation Science and Engineering, Harbin Institute of Technology, Harbin 150090, Heilongjiang, China. ${ }^{2}$ School of Civil Engineering, Harbin Institute of technology, Harbin 150090, China. ${ }^{3}$ Key Lab of Structures Dynamic Behavior and Control of the Ministry of Education, 9 Harbin Institute of Technology, Harbin 150090,

China. ${ }^{4}$ State Key Laboratory of Solid Waste Reuse for Building Materials, Beijing Building 11 Materials Academy of Science Research, Beijing 100041, China.

\section{References:}

[1] Wongkeo W, Chaipanich A (2010) Compressive strength, microstructure and thermal analysis of 
autoclaved and air cured structural lightweight concrete made with coal bottom ash and silica fume. MAT SCI ENG A-STRUCT 527: 3676-3684.

[2] Yang J, Shi Y, Yang X, Liang M, Li Y, Li Y et al (2013) Durability of autoclaved construction materials of sewage sludge-cement-fly ash-furnace slag. CONSTR BUILD MATER 48: 398-405.

[3] Ungkoon Y, Sittipunt C, Namprakai P, Jetipattaranat W, Kim K, Charinpanitkul T (2007) Analysis of microstructure and properties of autoclaved aerated concrete wall construction materials. J IND ENG CHEM 13: 1103-1108.

[4] Deng M, Zhang W, Yang S (2020) In-plane seismic behavior of autoclaved aerated concrete block masonry walls retrofitted with high ductile fiber-reinforced concrete. ENG STRUCT 219: 110854. doi: 10.1016/j.engstruct.2020.110854.

[5] Liu R, Huang Y (2018) Heat and moisture transfer characteristics of multilayer walls. ENERG PROCEDIA 152: 324-329.

[6] Hussin MW, Muthusamy K, Zakaria F (2010) Effect of mixing constituent toward engineering properties of POFA cement-based aerated concrete. J MATER CIVIL ENG 22: 287-295.

[7] Drochytka R, Zach J, Korjenic A, Hroudová J (2013) Improving the energy efficiency in buildings while reducing the waste using autoclaved aerated concrete made from power industry waste. ENERG BUILDINGS 58: 319-323.

[8] Narayanan N, Ramamurthy K (2000) Structure and properties of aerated concrete: A review. CEMENT CONCRETE COMP 22: 321-329.

[9] Stumm A, Schweike U, Stemmermann P (2018) Nanostructured high insulating autoclaved aerated concrete. MAUERWERK, 22: 329-334. DOI 10.1002/dama.201800024.

[10] Kalpana M, Mohith S (2020) Study on autoclaved aerated concrete: Review. MATER TODAY PROCEEDINGS 22: 894-896.

[11] Watson KL (1980) Autoclaved aerated concrete from slate waste Part 2: Some property/porosity relationships. INT J CEM COMPOS LIGHTWEIGHT CONCRETE 2: 121-123.

[12] Roulet CA (1983) Expansion of aerated concrete due to frost-Determination of critical saturation. In: Wittmann FH (ed) Proceedings Autoclaved Aerated Concrete, Moisture and Properties. Elsevier, Amsterdam.

[13] Jerman M, Keppert M, Výborný J, Černý R (2013) Hygric, thermal and durability properties of autoclaved aerated concrete. CONSTR BUILD MATER 41: 352-359.

[14] Prim P, Wittmann FH (1983) Structure and water absorption of aerated concrete. In: Wittmann FH (ed) Proceedings Autoclaved Aerated Concrete, Moisture and Properties. Elsevier, Amsterdam.

[15] Tada S, Nakano S (1983) Microstructural approach to properties of moist cellular concrete. In: Wittmann FH (ed) Proceedings Autoclaved Aerated Concrete, Moisture and Properties. Elsevier, Amsterdam.

[16] Koronthalyova O (2011) Moisture storage capacity and microstructure of ceramic brick and autoclaved aerated concrete. CONSTR BUILD MATER 25: 879-885.

[17] Fernández-Jiménez A, Palomo A, Criado M (2005) Microstructure development of alkali-activated fly ash cement: A descriptive model. CEMENT CONCRETE RES 35: 1204-1209.

[18] Qu X, Zhao X (2017) Previous and present investigations on the components, microstructure and main properties of autoclaved aerated concrete-A review. CONSTR BUILD MATER 135: 505-516.

[19] Ioannou I, Hamilton A, Hall C 2(008) Capillary absorption of water and n-decane by autoclaved aerated concrete. CEMENT CONCRETE RES 38: 766-771.

[20] Cong X, Lu S, Yao Y, Wang Z (2016) Fabrication and characterization of self-ignition coal gangue autoclaved aerated concrete. MATER DESIGN 97: 155-162. 
[21] Chinese National Standard (2009) Test methods for performance of autoclaved aerated concrete (GB/T 11969-2008), China building industry press, Beijing. 


\section{Figures}

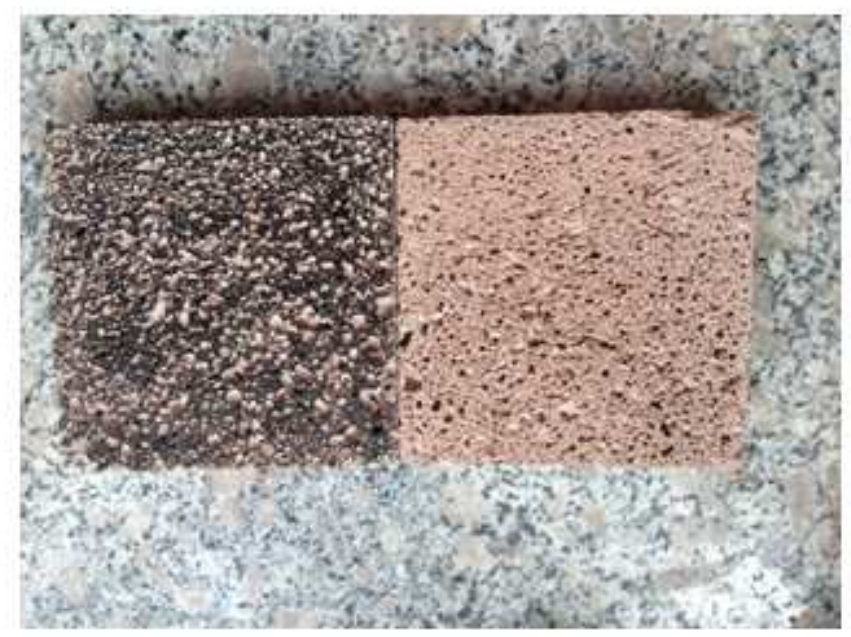

a)

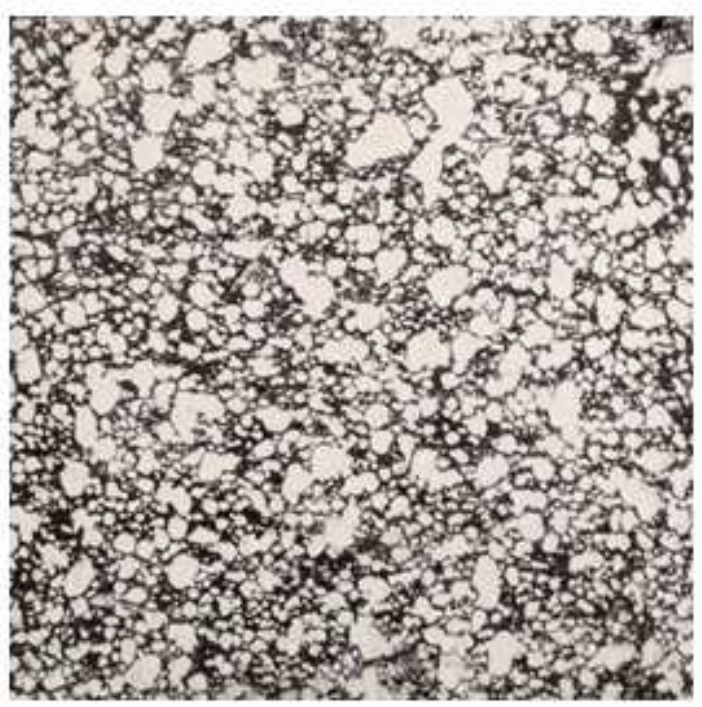

b)

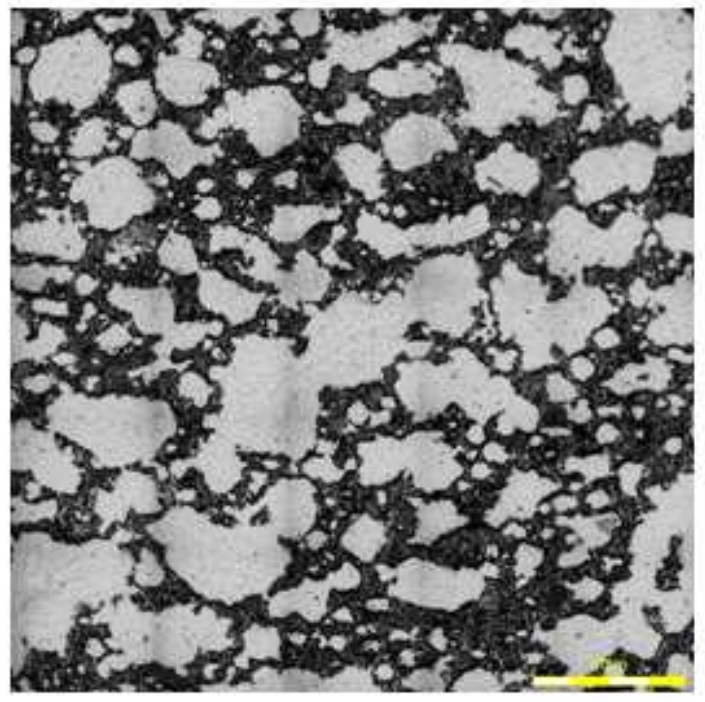

c)

\section{Figure 1}

Super depth of field microscope (SDFM) images for pore characterization of SCGAAC: a) black-painting slice vs. original slice; b) pore-filling slice; $c$ ) capture image. 


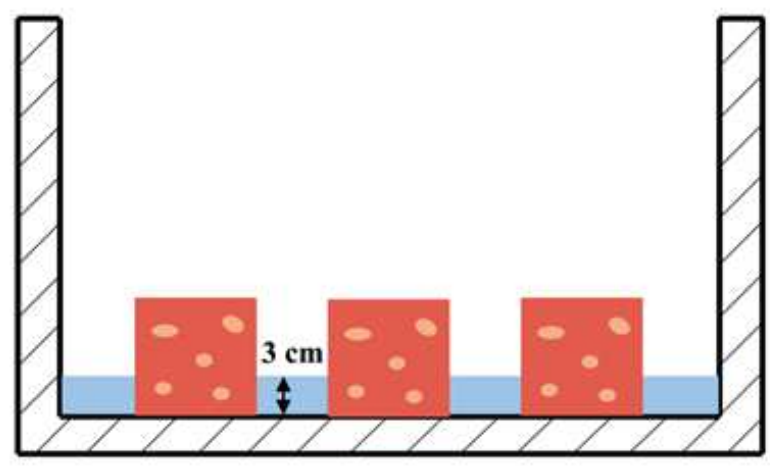

a)

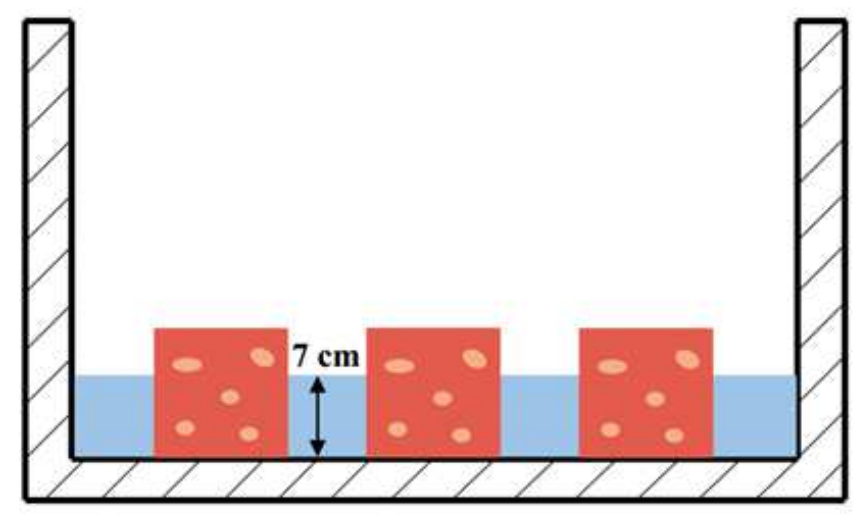

b)

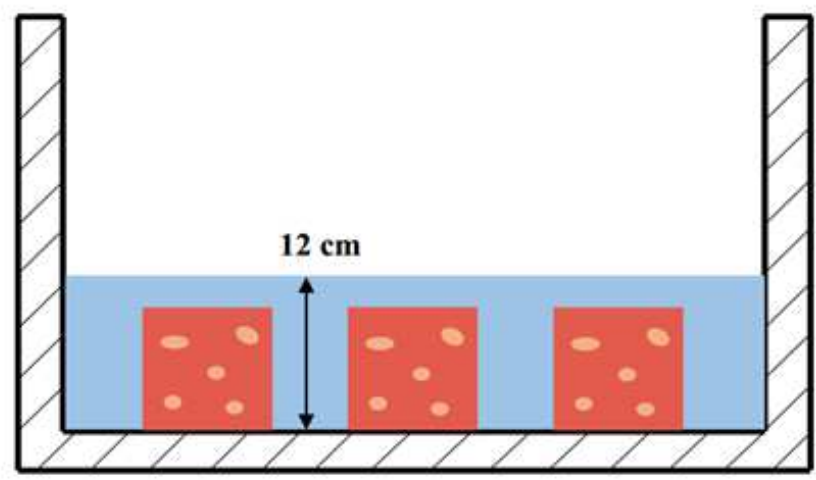

c)

Figure 2

The protocol of water absorption test: a) the water volume for the first $24 \mathrm{~h} ; \mathrm{b}$ ) the water volume for the second $24 \mathrm{~h}$; ) the water volume for the third $24 \mathrm{~h}$. 


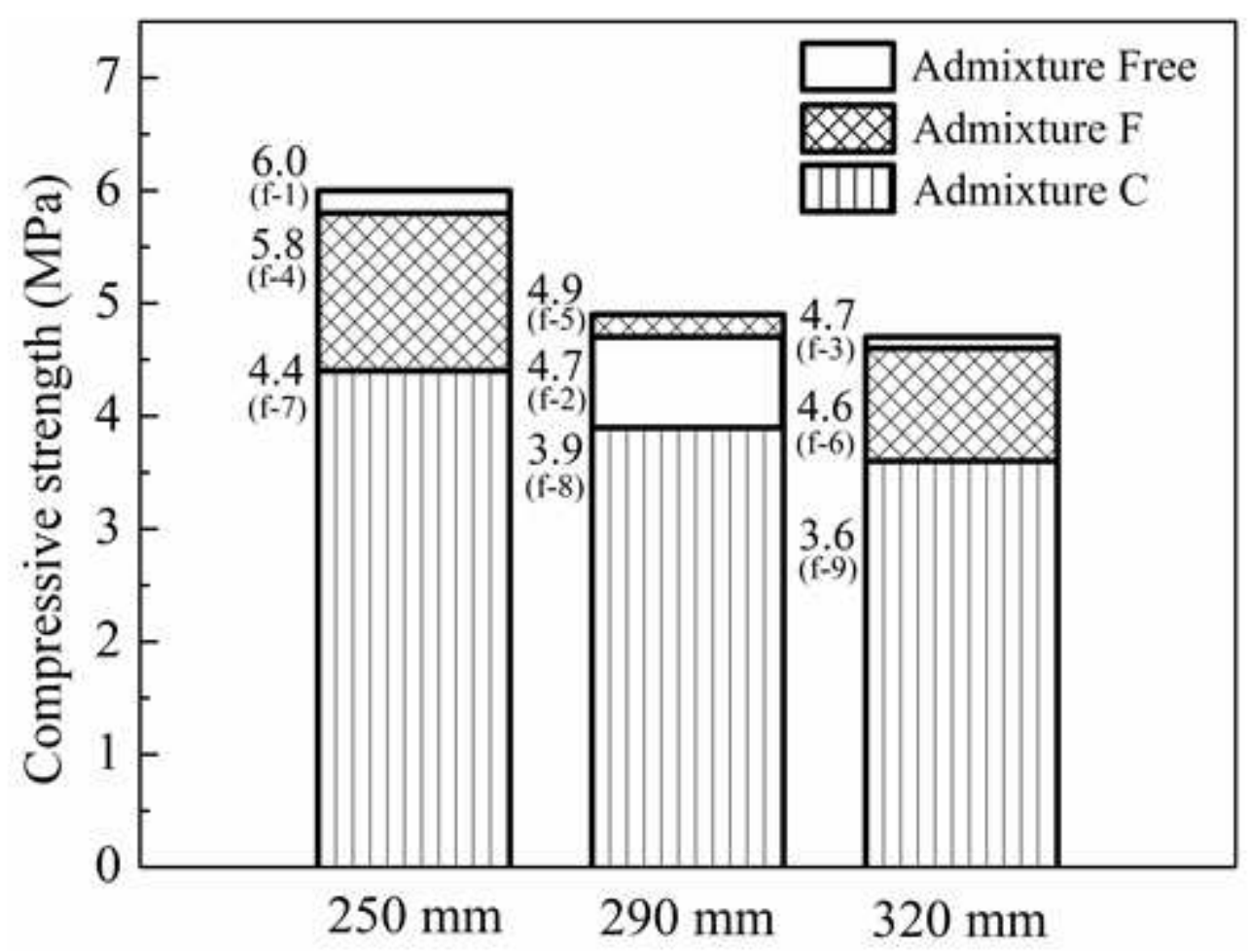

Figure 3

Compressive strength of SCGAAC.

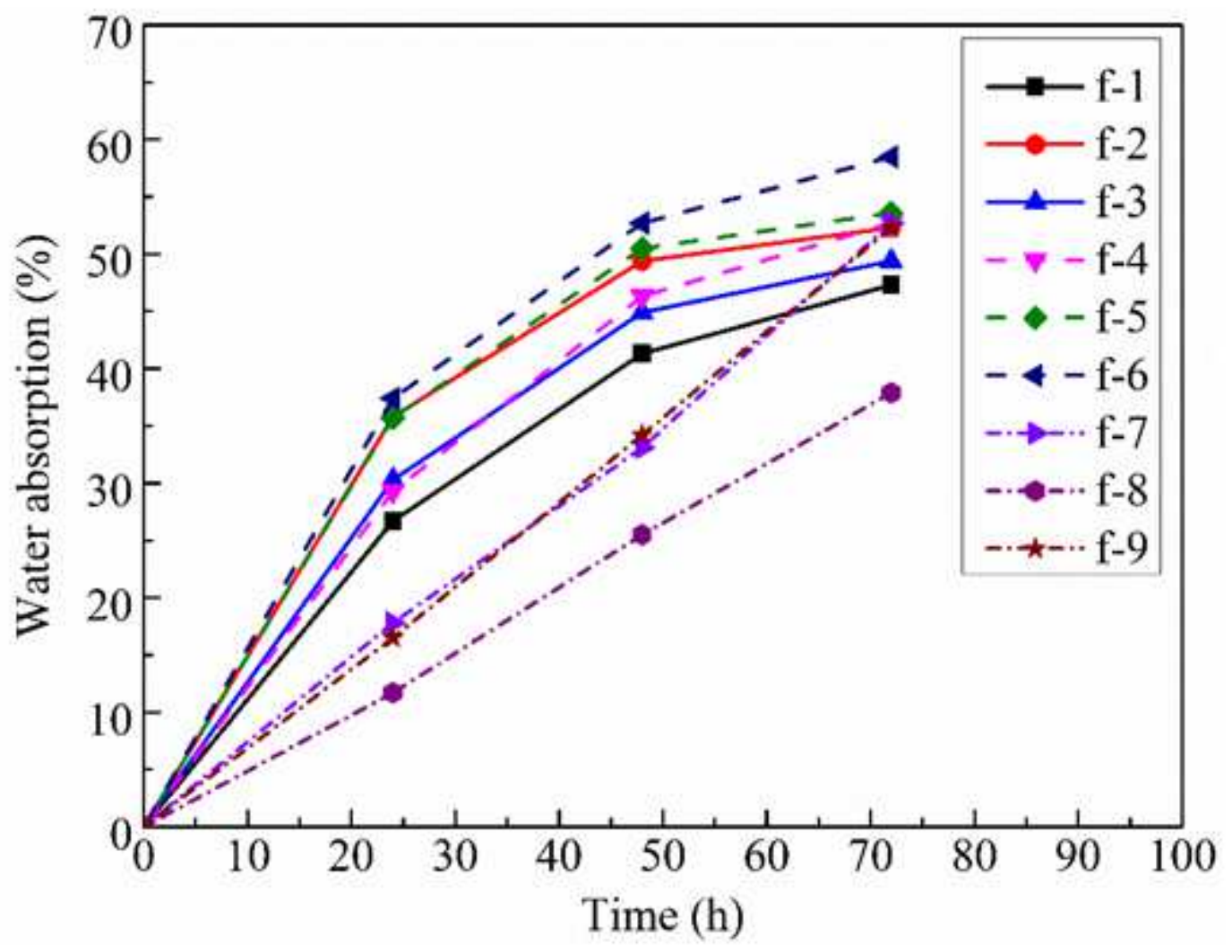

Figure 4 
Water absorptivity of SCGAAC.

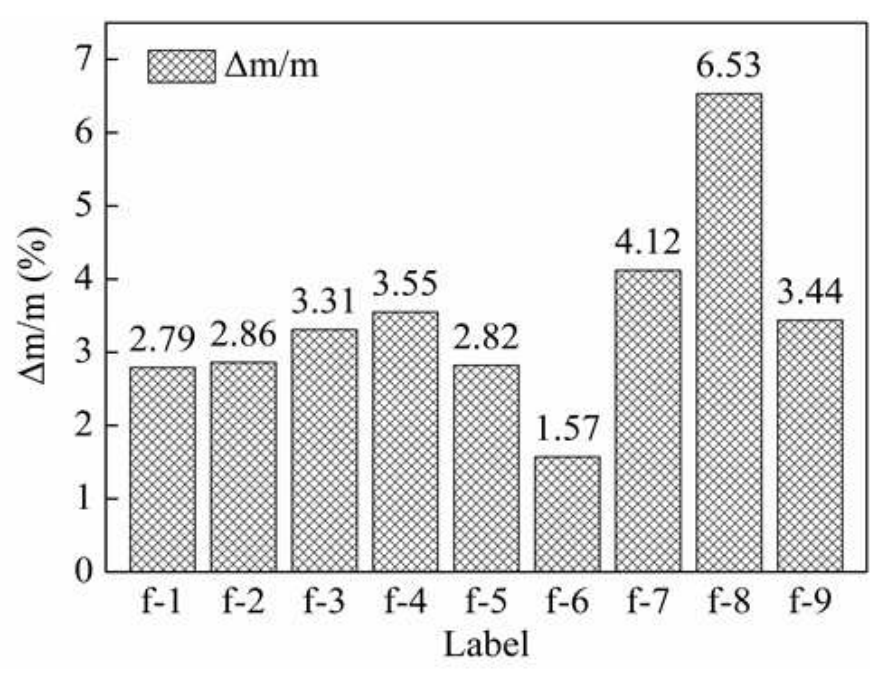

a)

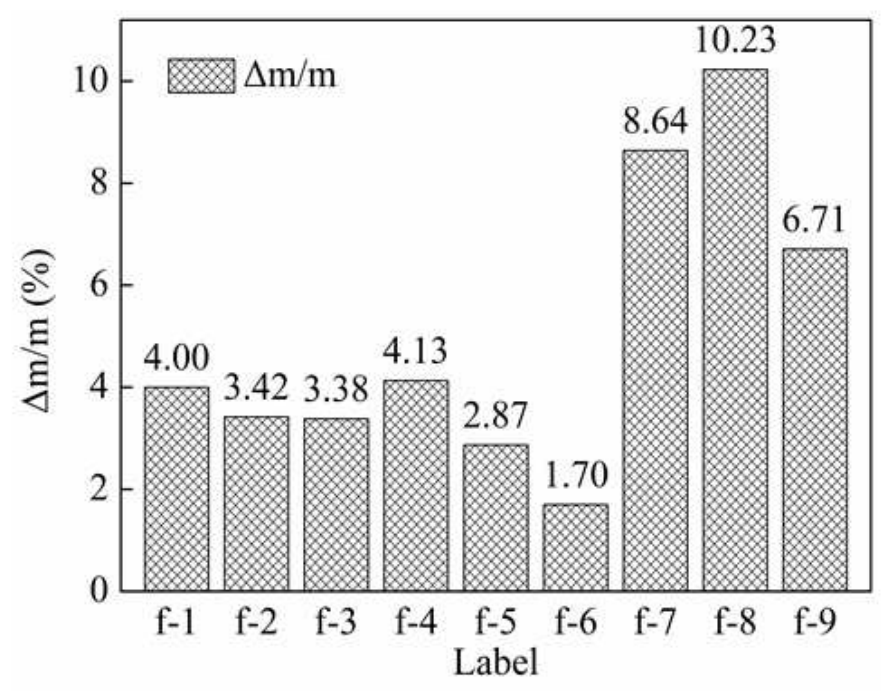

b)

\section{Figure 5}

Mass change of SCGAAC subjected to a different number of freezing-thawing circles: a) after 25 freezingthawing cycles; and b) after 50 freezing-thawing cycles.

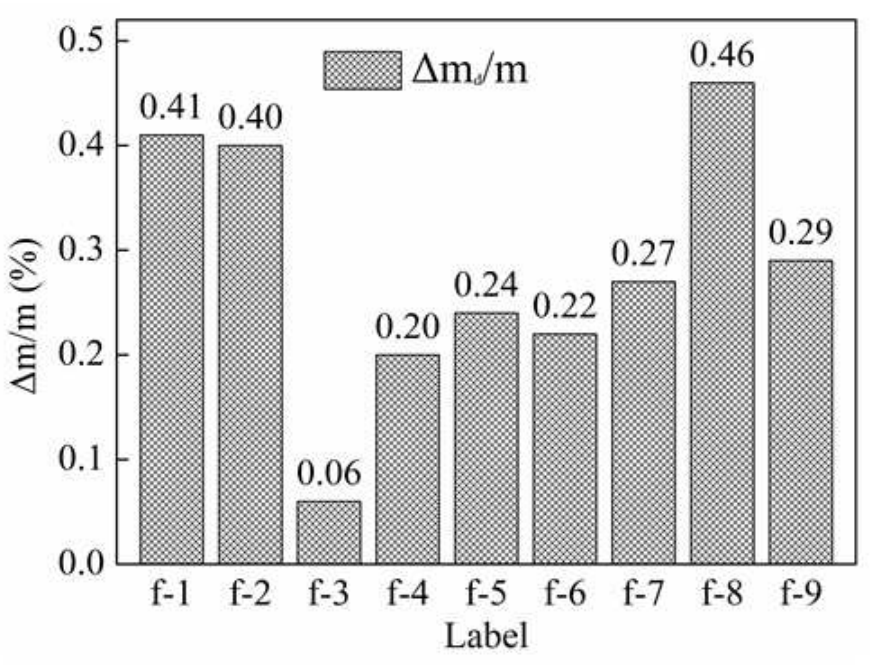

a)

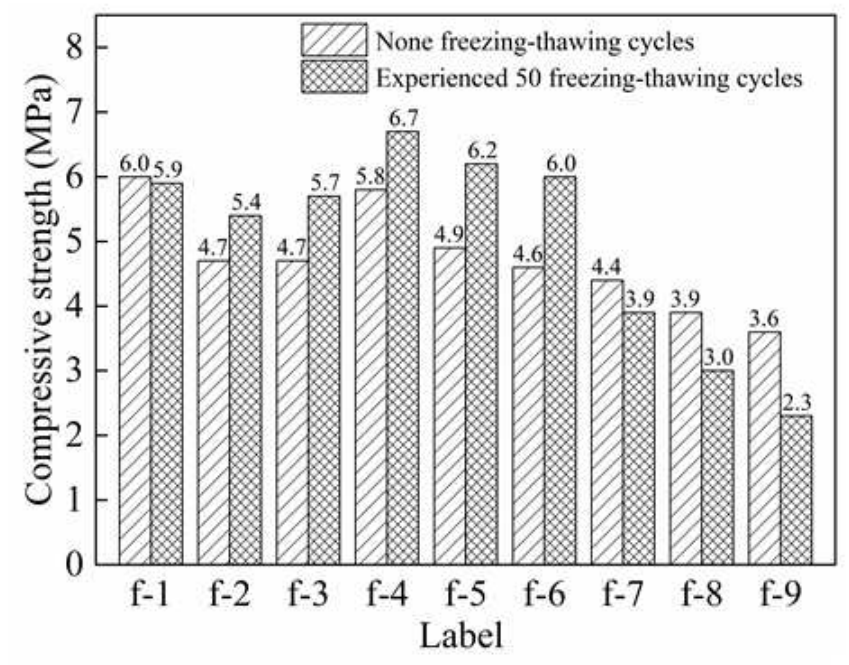

b)

Figure 6

Difference of SCGAAC subjected to 50 freezing-thawing cycles: a) absolutely dried mass; and b) compressive strength. 


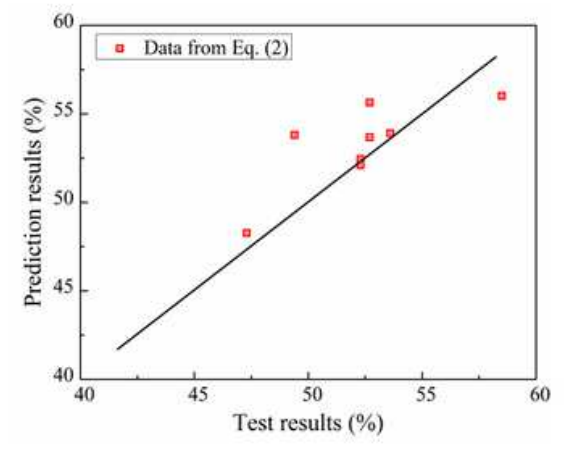

a)

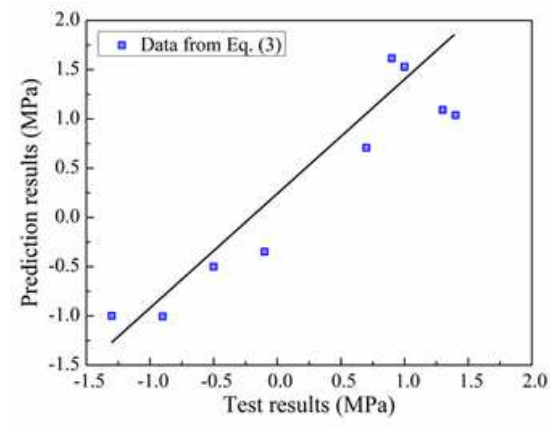

b)

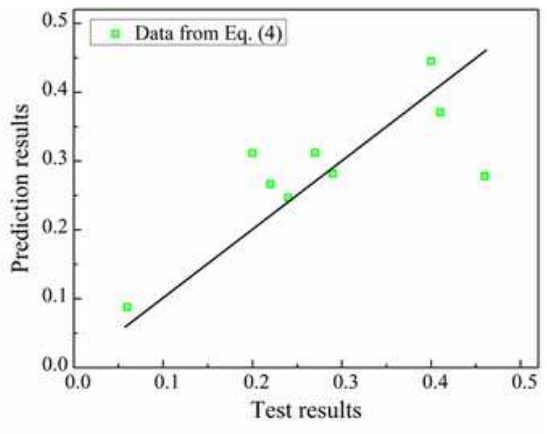

c)

\section{Figure 7}

Comparison between prediction results and test results: a) data from Eq. (2); b) data from Eq. (3); and c) data from Eq. (4). 